\title{
Physiological Effects of a Modification of the Construction of Impermeable Protective Clothing
}

\author{
Anna Marszałek \\ Department of Ergonomics, Central Institute for Labour Protection - National Research \\ Institute (CIOP-PIB), Warszawa, Poland
}

\author{
Grażyna Bartkowiak \\ Krzysztof tężak
}

\section{Department of Protective Clothing, Central Institute for Labour Protection - National Research Institute (CIOP-PIB), tódź, Poland}

This study was conducted to improve the construction of impermeable clothing protecting against liquid chemical agents in order to lower the thermal strain caused by the clothing during work. Previous studies indicated that light work in a hot environment in this kind of clothing could last 30 min only. We propose a modification of the construction; new models of protective clothing were tested in wear trials. Then the results were compared with a basic model of impermeable protective clothing. Results indicated that all new models of protective clothing allowed workers to work 39-64\% longer than in a basic model of protective clothing. Thus new clothing significantly improved comfort of work in impermeable protective clothing because of the lower thermal strain that it imposed on the user.

hot environment protective clothing physiological responses

\section{INTRODUCTION}

Protective clothing should reduce the influence of environmental hazards. On the one hand it ought to ensure proper protection, on the other fulfil ergonomic requirements [1]. Protection against physical and chemical hazards in most cases means special fabrics or their special treatment which makes the fabrics to a high extent impermeable [2].

Protective clothing impermeable to air and water vapour affords good protection against chemical agents present in the surroundings but makes heat exchange between the human body and the environment difficult [1]. As a result there is often an increase in physiological and psychological strain, a decrease in the ability to work or an increase in discomfort especially in the case of impermeable protective clothing in a hot environment $[3,4,5,6]$.

When the air temperature is higher than the mean skin temperature, sweat evaporation is the only way of removing excess heat from the body. Physical features of impermeable protective clothing disturb sweat evaporation; therefore, sweat accumulates in underwear. As a result

This task was carried out within the scope of the second stage of the National Programme "Adaptation of Working Conditions in Poland to European Union Standards", partly supported in 2005-2007-within the scope of research-by the Ministry Science and Higher Education and-within the scope of state services-by the Ministry of Economy and Labour. The Central Institute for Labour Protection - National Research Institute was the Programme's main co-ordinator.

Correspondence and requests for offprints should be sent to Anna Marszałek, Department of Ergonomics, Central Institute for Labour Protection - National Research Institute, Czerniakowska 16, 00-701 Warszawa, Poland. E-mail: <anmar@ ciop.pl>. 
air humidity under the impermeable layer of protective clothing increases and physiological parameters and subjective assessment deteriorate [7]. More impermeable protective clothing causes a higher risk of discomfort and higher thermal load for the user $[8,9,10]$; thus work time must be limited [11].

In some cases work under physical or chemical exposure has to be done for a longer time than advisable in view of safety, e.g., during an emergency or a traffic accident, where there is a need for immediate action to protect the health or life of injured people or to protect the ground against contamination. In those conditions the possibility of prolonged work in protective clothing has some advantages.

Our previous study let us determine work time in selected protective clothing [7]. The present study aimed at conducting physiological studies with modified models of protection clothing to identify the more comfortable ones and the ones that ensured a longer duration of use.

\section{METHODS}

\subsection{Subjects}

Six fire-fighters participated in the study. Their descriptive characteristics $(M \pm S D)$ were (a) age: $29.0 \pm 3.7$ years, (b) height: $1.83 \pm 0.70 \mathrm{~m}$, (c) weight: $80.3 \pm 4.8 \mathrm{~kg}$, and (d) physical fitness: $40.3 \pm 2.1 \mathrm{ml} \mathrm{V} \mathrm{O} \cdot \mathrm{kg}^{-1} \cdot \mathrm{min}^{-1}$. The subjects were fully informed of the purpose and procedures, and signed a statement of informed consent.

\subsection{Protective Clothing Tested in the Study}

Chemical protective clothing L2 available on the Polish market, used by military and civil services and fire-fighters, was used in the study (Figure 1). The model was designed to protect workers against splashes of acids or alkalis during shortterm work. It was made of a polyamide fabric that weighed $300 \pm 20 \mathrm{~g} \cdot \mathrm{m}^{-2}$ and was coated on both sides with a rubber mixture based on butyl rubber. The model consisted of a boiler suit with a hood and it had wellingtons glued permanently to the trousers. Type L2 suits meet the essential requirements of Directive 89/686/EEC [12] and
Standard No. EN14605:2005 [13] on garments protecting against liquid chemicals. It is type 3 of chemical protective clothing.

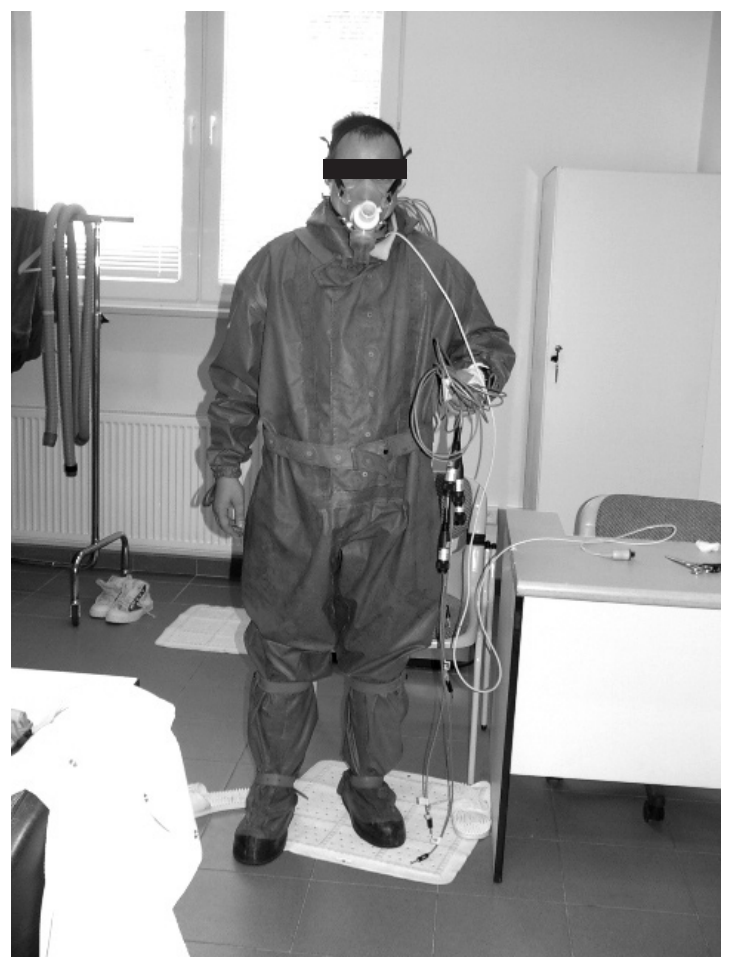

Figure 1. Basic model, protective clothing L2.

The construction of the basic L2 model was modified.

- Prototype A had profiled vertical tunnels on the level of the waist, which made air flow between the lower and upper parts of clothing easier (Figure 2). It also had ventilation holes in the front and back sides of the upper part of the clothing covered with a thin, permeable net fabric. Moreover, it had a kind of cloak with shorter sleeves over the upper part of the clothing to protect against liquid chemicals.

- Prototype B was equipped with refills of high sorption fabrics, which were inserted in seven $0.14 \times 0.40 \mathrm{~m}$ pockets: two pockets in the upper part of the trousers in the front and two in the back, and three pockets in the upper part of the overalls, i.e., one pocket on the right and one on the left part of the chest and a double pocket on the back (Figure 3).

- Prototype C was similar to prototype A but it was also equipped with a ventilator which delivered air from the outside. The air was then distributed inside the clothing through 

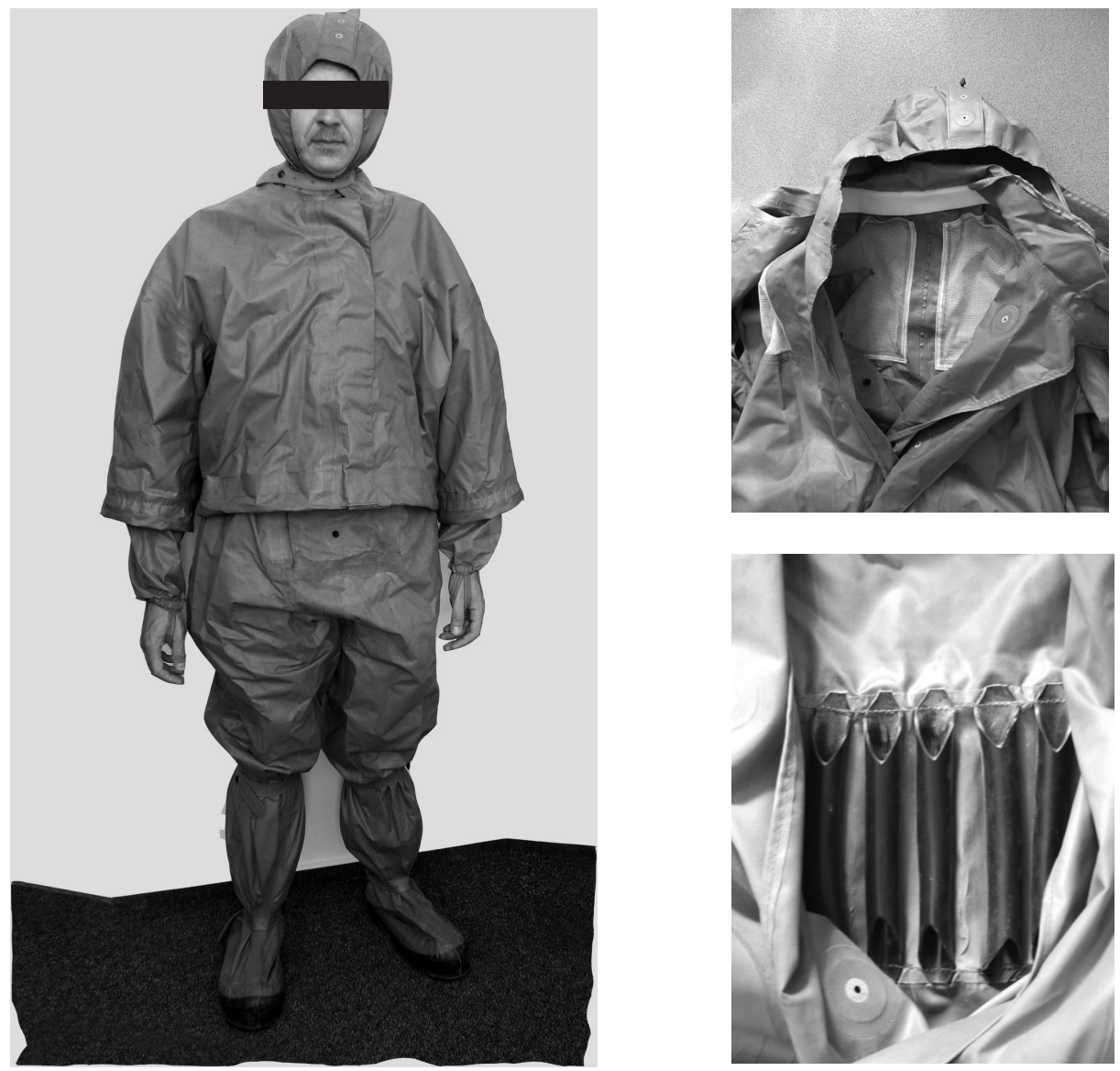

Figure 2. Prototype A of protective clothing.
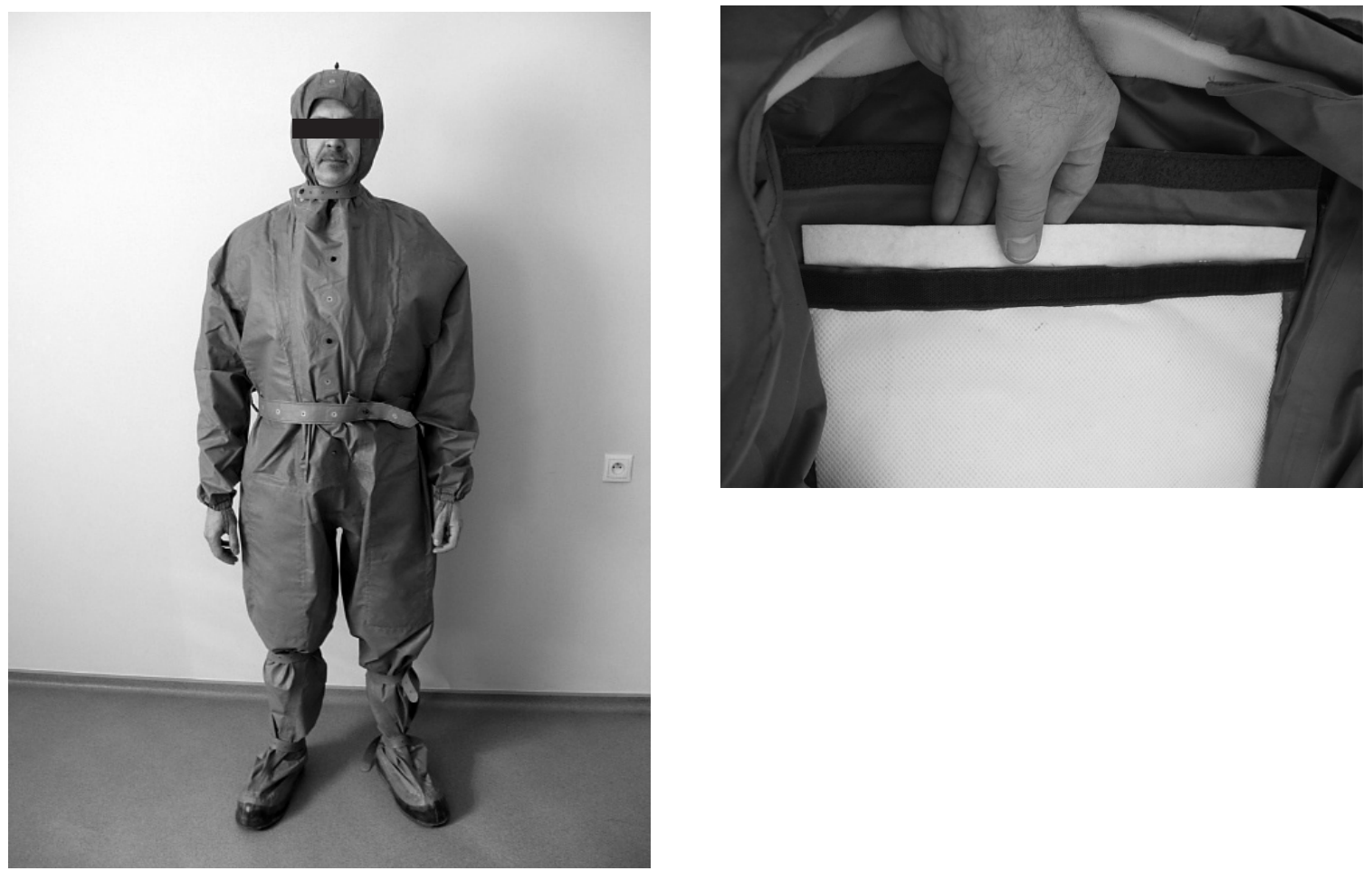

Figure 3. Prototype B of protective clothing. 

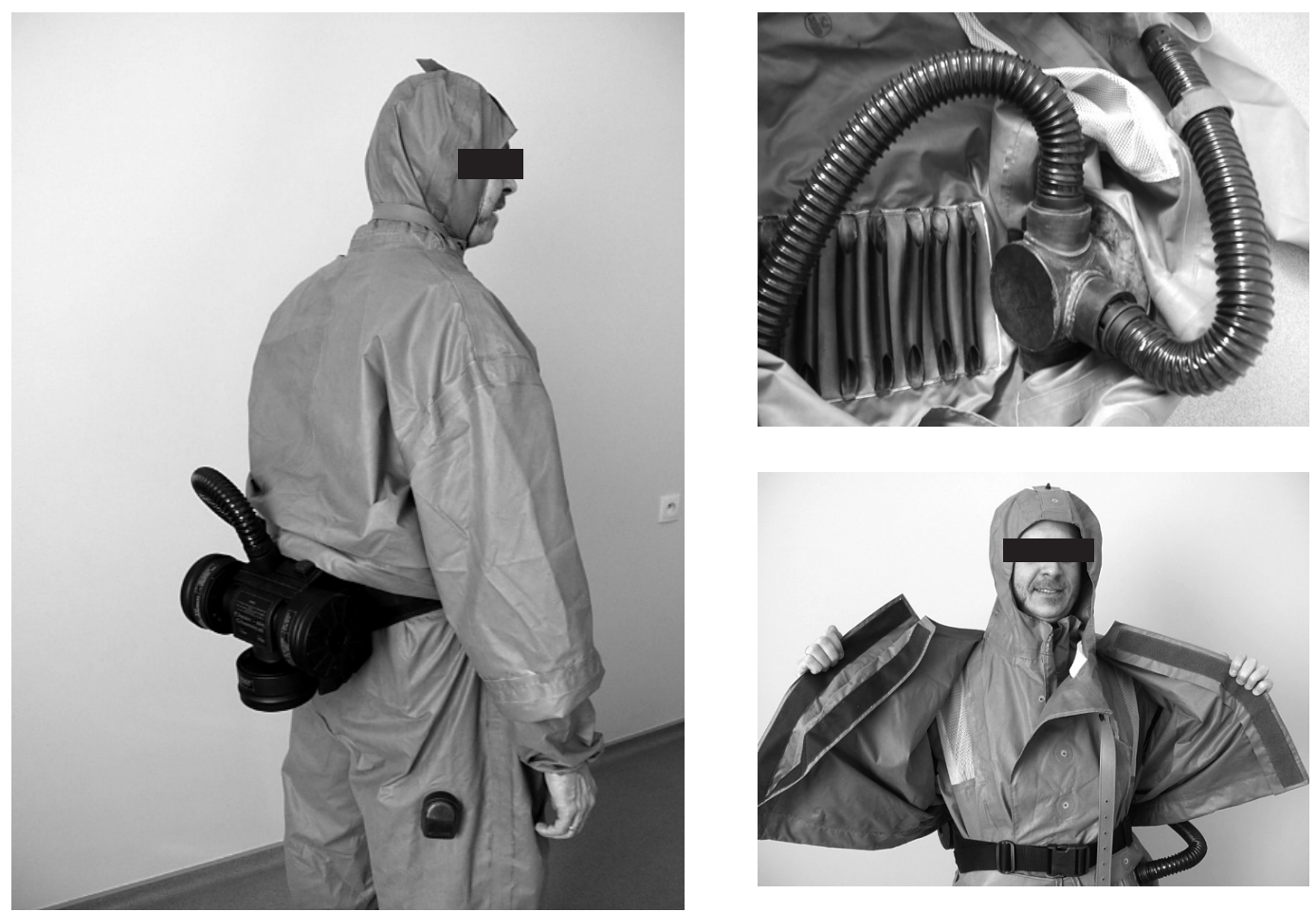

Figure 4. Prototype $\mathrm{C}$ of protective clothing.

wide pipes directed at the legs and at the chest. There were two exit valves outside the legs (Figure 4). The ventilator made air flow with a speed of a minimum of $120 \mathrm{~L} / \mathrm{min}$ possible.

In all experiments the subjects wore cotton underwear with long sleeves and legs, and cotton socks.

Prototypes A, B and C were made of the same basic material as the L2 suit but garment construction was modified. So, two parameters characterizing the tightness of this construction were studied: (a) resistance to penetration of liquid sprays (the spray test) [14] and (b) resistance to penetration of poured liquid (the jet test) [15]. The modified protective clothing was found to be tight with regard to penetration of liquid sprays and jets and to fulfil the requirements of Standard No. EN14605:2005 [13].

\subsection{Thermal and Physical Load}

The study was conducted in a climatic chamber in air temperature of $40{ }^{\circ} \mathrm{C}, 30 \%$ relative humidity and wind speed of $0.2 \mathrm{~m} / \mathrm{s}$. The participants walked on a treadmill with the speed of $3 \mathrm{~km} / \mathrm{h}$.

The exercise was continued until one of the following limits was reached: core temperature of $38.0{ }^{\circ} \mathrm{C}$, heart rate of $80 \%$ of the individual maximum heart rate, $100 \%$ relative humidity measured at least in two places (under the protective clothing), or objective or subjective signs of fatigue.

\subsection{Measurements}

Core temperature in the external auditory canal $\left(t_{\mathrm{ac}}\right)$, skin temperature $\left(t_{\mathrm{sk}}\right)$ in four places [16], heart rate as well as temperature and relative humidity under clothing in four places (right side of the chest, left shoulder, left arm, right thigh) were monitored every minute. Mean weighted skin temperature, $\bar{t}_{\mathrm{sk}}$, was calculated according to Standard No. EN ISO 9886:2004 [16]. Body and clothing were weighed before and after exposure. Sweat loss was calculated as the difference between body weight after and before exposure to heat. Subjective ratings of climate [17] and skin wettedness [18] were collected every $10 \mathrm{~min}$. 


\subsection{Treatment of Data}

Statistical differences were determined using analysis of variance $(p=.05)$ taking conditions of test performance into account. Homogeneity of variance was checked with the Leven test. Differences among individual physiological or subjective values were assessed with the NIR test because some subjects did not participate in all experiments and were substituted with others.

\section{RESULTS}

\subsection{Duration of Exposure}

Duration of exposure to light work in a hot environment in different types of protective clothing lasted $41.7 \pm 6.0,45.0 \pm 3.2,49.2 \pm$ 4.9 and $30.0 \pm 5.5 \mathrm{~min}$ in experiments with prototypes A, B, C and in protective clothing L2, respectively (Figure 5). Work time was statistically significantly $(p<.05)$ shorter in clothing L2 than in each of the prototypes. Moreover, duration of exposure in prototype $\mathrm{C}$ was statistically significantly $(p<.05)$ longer than in prototype A. Duration of the exposure was longer by 39,50 or $64 \%$ in prototypes A, $\mathrm{B}$ and $\mathrm{C}$, respectively, compared to exposure in protective clothing L2.

\subsection{External Auditory Canal Temperature}

Changes in $t_{\mathrm{ac}}$ were slower in experiments with all prototypes than with L2 clothing, with the differences statistically significant in the 30th minute of the experiment. The increase in $t_{\mathrm{ac}}$ was also statistically significantly lower in prototype $\mathrm{C}$ than in $\mathrm{A}$ and $\mathrm{B}$ in the 40th minute of the experiment. Figure 6 illustrates the details. The final result of $t_{\mathrm{ac}}$ in prototypes $\mathrm{A}$ and $\mathrm{B}$ was slightly lower than previous measurements; not all subjects participated in this stage of the experiment because some of them sooner achieved limit values of the measured parameters.

\subsection{Mean Weighted Skin Temperature}

The level of $\bar{t}_{\mathrm{sk}}$ was lower in all prototypes than in protective clothing L2 from the 20th minute of the experiments; the differences became statistically significant in the 30th minute of exposure. Like in $t_{\mathrm{ac}}$, changes in $\bar{t}_{\mathrm{sk}}$ were statistically significantly $(p<.05)$ lower in experiments with prototype $\mathrm{C}$ than $\mathrm{A}$ and $\mathrm{B}$ in the 40th minute of the study (Figure 7). If $\bar{t}_{\mathrm{sk}}$ achieved the level of $38 \pm 0.1^{\circ} \mathrm{C}$ in the 30th minute of the experiments with $\mathrm{L} 2$ and in the 45th and 50th minutes of the experiment with prototypes $\mathrm{A}$ and $\mathrm{B}$, respectively, in prototype $\mathrm{C}$ the subjects ended the experiments in the 55th minute with $\bar{t}_{\mathrm{sk}}$ still as low as 37.7 $\pm 0.0^{\circ} \mathrm{C}$.

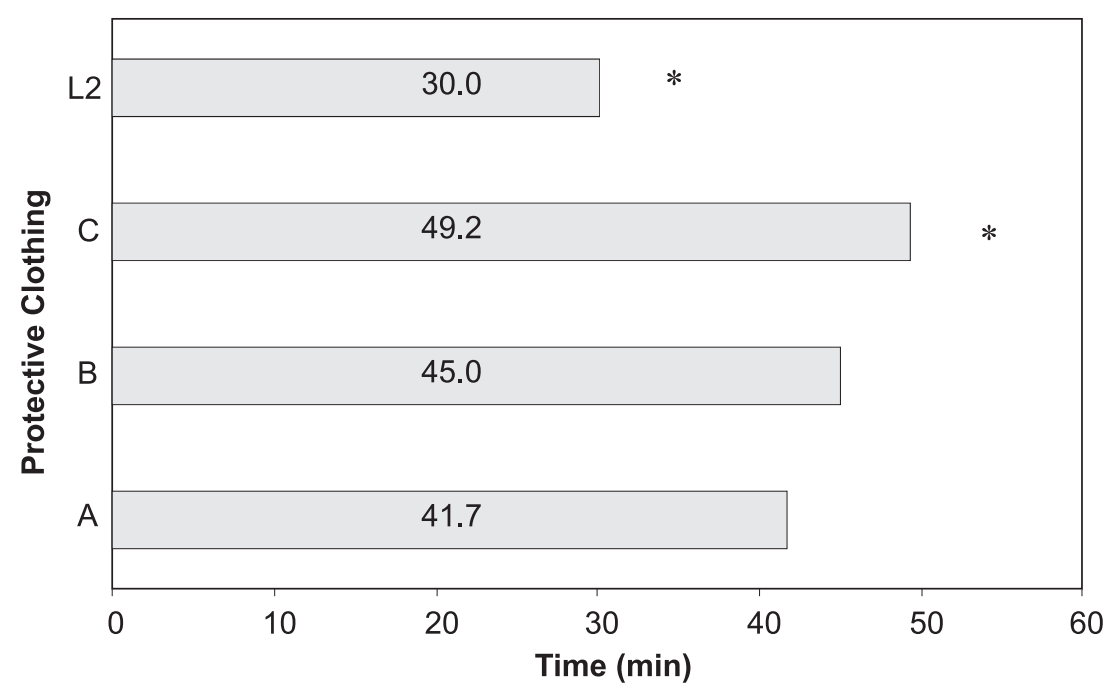

Figure 5. Duration of experiments with prototypes A, B, C and with protective clothing L2. Notes. ${ }^{*} p<.05$ among $\mathrm{L} 2$ and all prototypes of protective clothing, and between prototypes $\mathrm{C}$ and $\mathrm{A}$. 


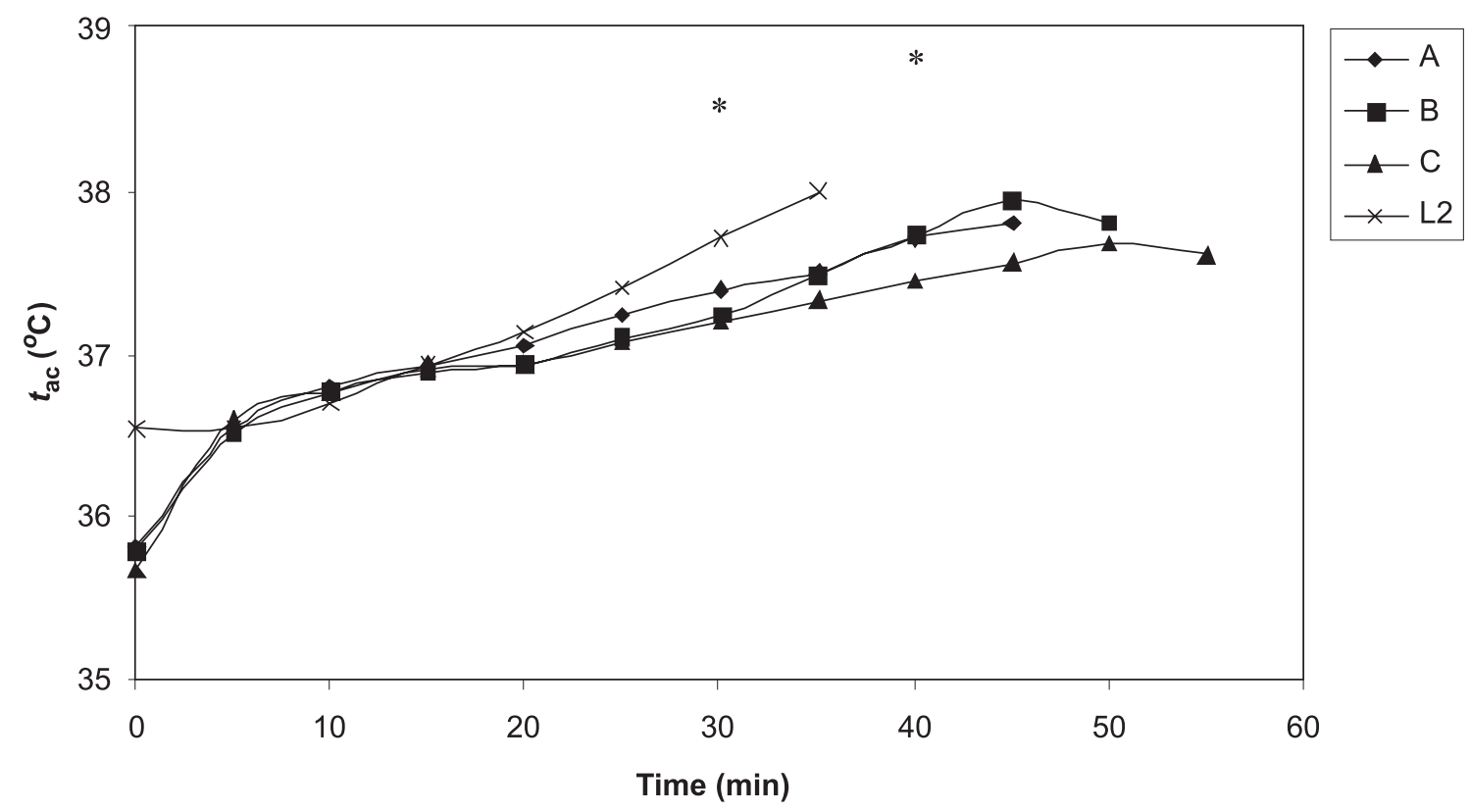

Figure 6. Time course of internal temperature measured in the external auditory canal $\left(t_{\mathrm{ac}}\right)$ during studies with prototypes A, B, C and with protective clothing L2. Notes. ${ }^{*} p<.05$ among L2 and all prototypes of protective clothing, and among prototypes A, B and C (40th minute); $t_{\mathrm{ac}}-$ core temperature in the external auditory canal.

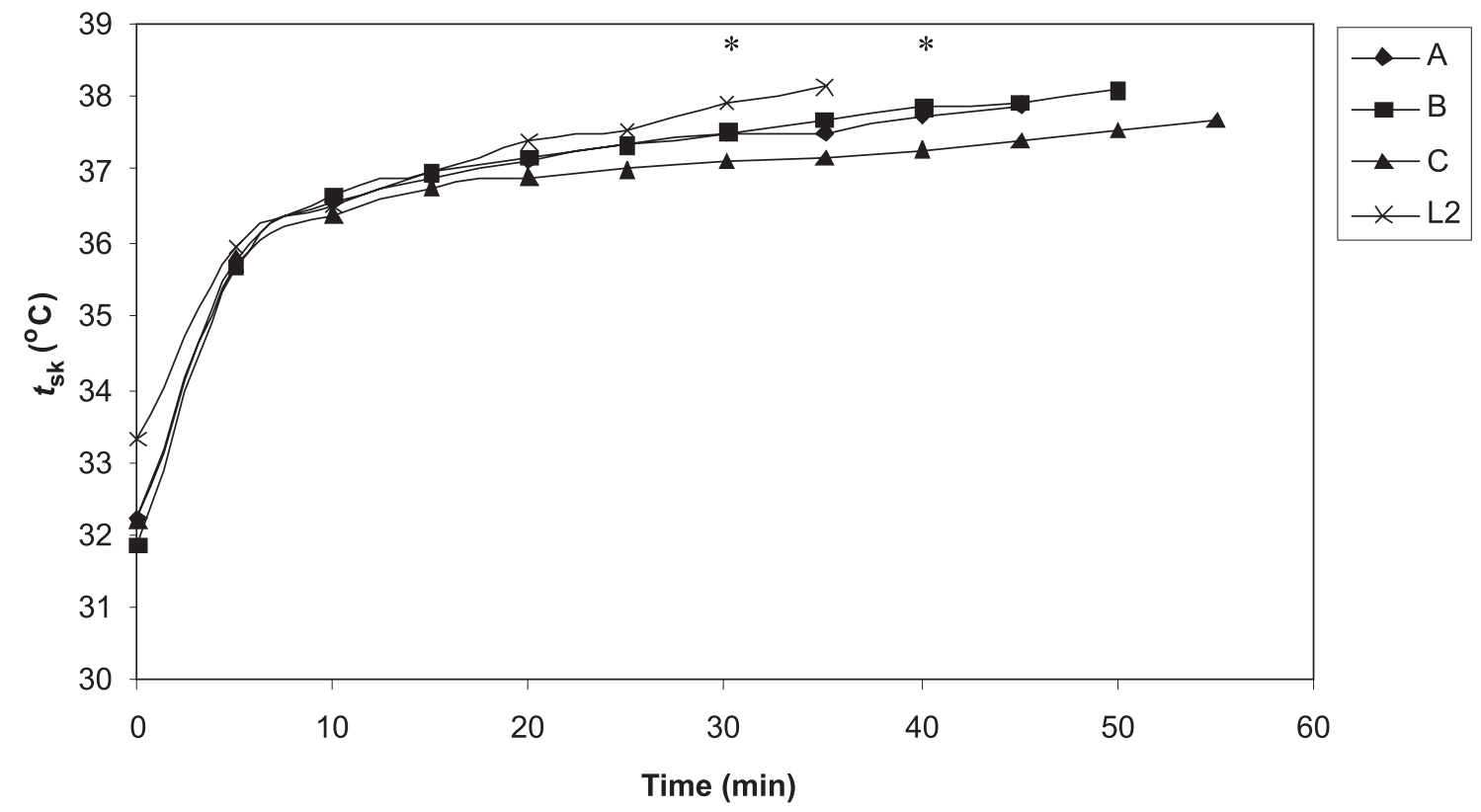

Figure 7. Time course of mean weighted skin temperature $\left(t_{\mathrm{sk}}\right)$ during studies with prototypes $\mathrm{A}, \mathrm{B}$, $\mathrm{C}$ and with protective clothing L2. Notes. ${ }^{*} p<.05$ among L2 and all prototypes of protective clothing, and among prototypes $\mathrm{A}, \mathrm{B}$ and $\mathrm{C}$ (40th minute). 


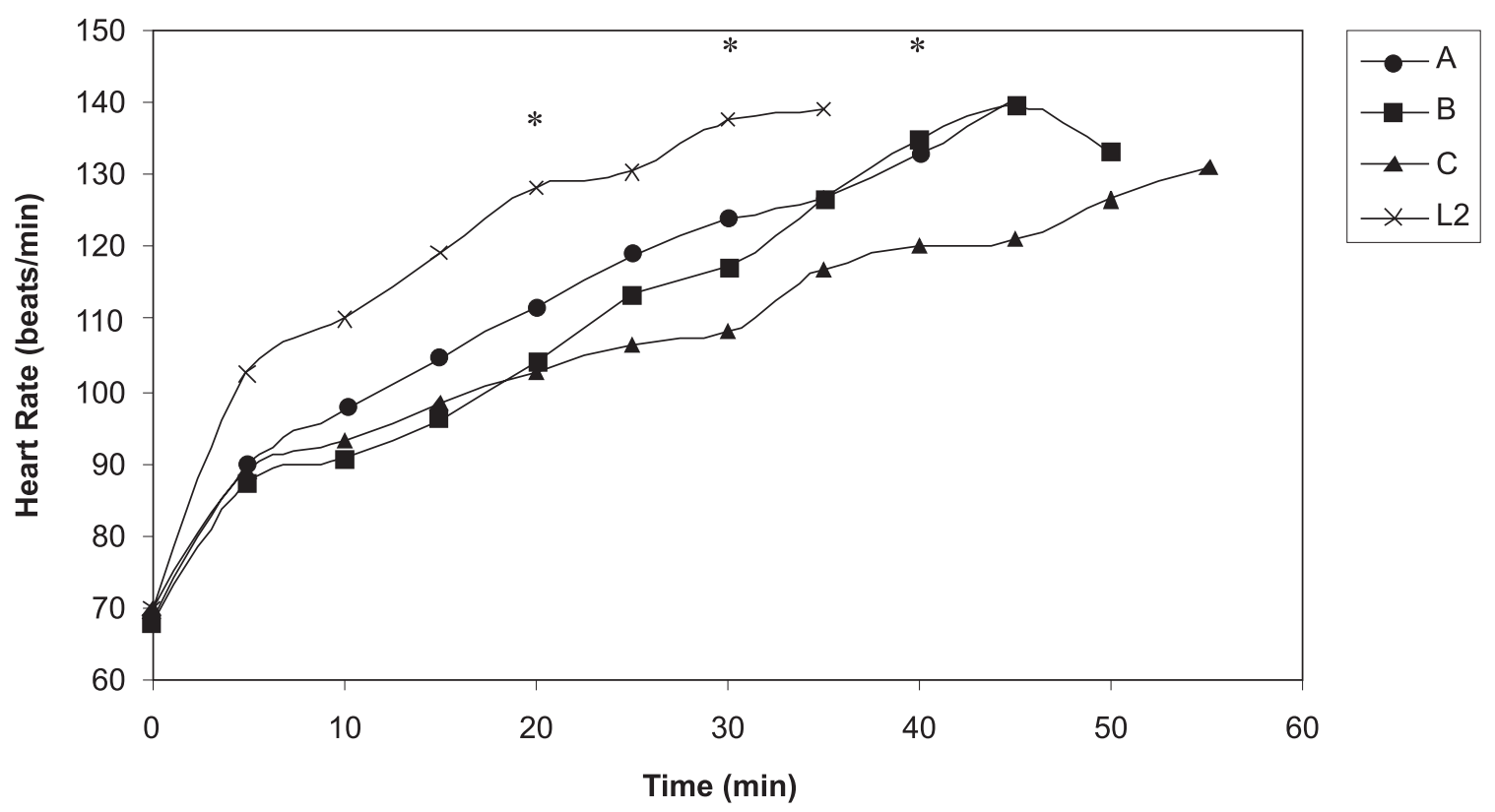

Figure 8. Time course of heart rate during studies with prototypes $A, B, C$ and with protective clothing L2. Notes. ${ }^{*} p<.05$ among L2 and all prototypes of protective clothing, and among prototypes A, B and $C$ (40th minute).

\subsection{Heart Rate}

Heart rate was lower in all prototypes than in protective clothing L2 from the 5th minute of the experiments. The differences were statistically significant $(p<.05)$ in the 20th and the 30th minutes of the study. Moreover, exercise in prototype $\mathrm{C}$ resulted in a lower increase in heart rate from the 25 th minute of the experiments than in prototypes $\mathrm{A}$ and $\mathrm{B}$; they were statistically significant $(p<.05)$ in the 30th and 40th minutes of the study (Figure 8).

\subsection{Temperature and Relative Humidity Under Clothing}

After a rapid increase in the first $5 \mathrm{~min}$ from the beginning of exposure, the mean temperature under clothing was rather stable in experiments with different kinds of protective clothing. However, the temperature was the lowest in the experiment with prototype $\mathrm{C}$ at $37.5 \pm 0.63{ }^{\circ} \mathrm{C}$ in the 55th minute of the experiment. The end values of the temperature under clothing were $38.0 \pm$ $0.2,38.8 \pm 0.0$ and $38.7 \pm 0.3{ }^{\circ} \mathrm{C}$ in prototypes $\mathrm{A}$, $\mathrm{B}$ and L2, respectively, but not at the same time of the experiment (see section 3.1.). The level of temperature under clothing was statistically significantly lower $(p<.05)$ in the 10th, 30th and 40th minutes of exposure in the experiments with prototype $\mathrm{C}$ than with $\mathrm{L} 2$. The temperature under clothing was also statistically significantly lower $(p<.05)$ in the experiments with prototype $\mathrm{C}$ than with B.

Figure 9 illustrates mean values of relative humidity under clothing calculated for all the kinds of clothing under study. In this case, too, changes in relative humidity under clothing throughout exposure were lower in experiments with all prototypes than with L2 clothing. Statistically significant differences were observed in the 10th and 20th minutes of the experiments $(p<.05)$. Moreover, mean values of relative humidity under clothing tended to be lower in experiments with prototype $\mathrm{C}$ than with prototypes $\mathrm{A}$ and $\mathrm{B}$; however, the differences were not significant.

\subsection{Sweating}

Experiments with different kinds of protective clothing were not equally long, so the intensity of sweating is given per minute, not per whole experiment. The intensity of sweating was $16.7 \pm$ $3.2,15.8 \pm 3.4,17.2 \pm 2.5$ and $20.9 \pm 5.8 \mathrm{~g} \cdot \mathrm{min}^{-1}$ for the experiments with protective clothing A, B, $\mathrm{C}$ and L2, respectively. The differences were not statistically significant. 
On the basis of the intensity of sweating and the amount of sweat accumulated in each part of clothing we calculated the amount of sweat which evaporated from the subjects' body surface. The results indicated that during the experiment with prototype $\mathrm{C}$ the amount of sweat which evaporated was statistically significantly $(p<.05)$ higher and the amount of sweat which accumulated in the clothing was statistically significantly $(p<.05)$ lower than in experiments with prototypes $\mathrm{A}$ and $\mathrm{B}$ and in L2 clothing (Figure 10).

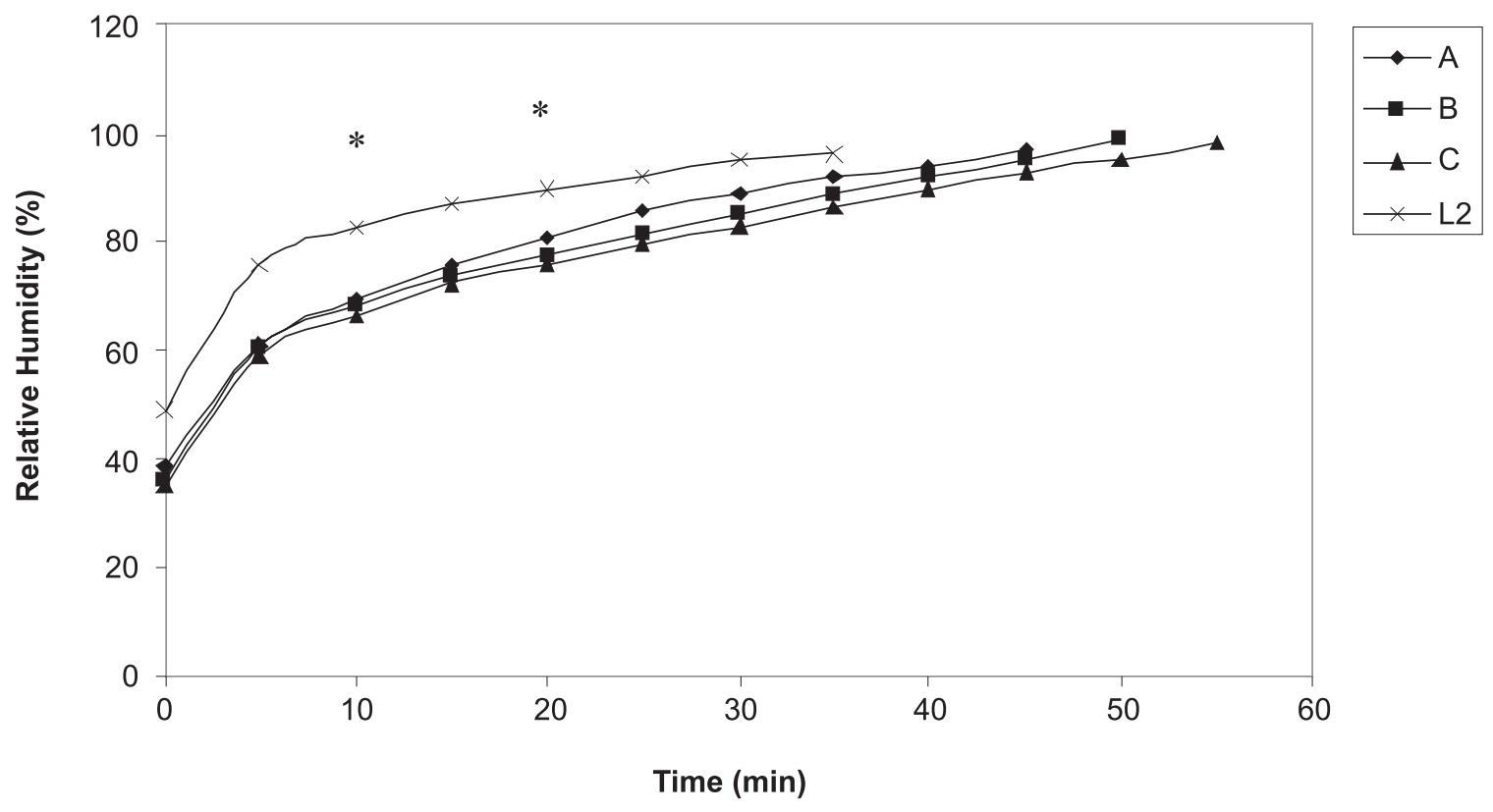

Figure 9. Time course of mean relative humidity under clothing during studies with prototypes A, B, $\mathrm{C}$ and with protective clothing L2. Notes. ${ }^{*} p<.05$ among L2 and all prototypes of protective clothing.

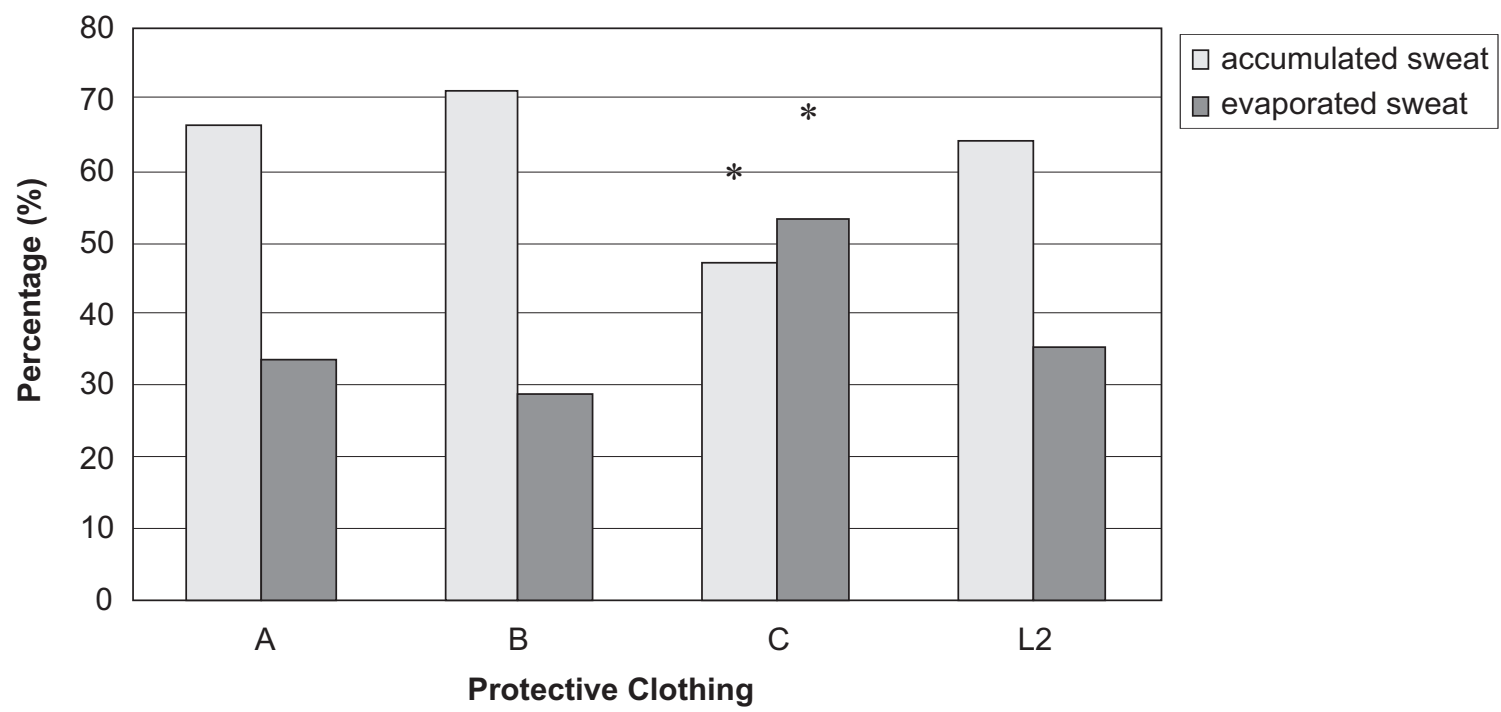

Figure 10. Sweat accumulated in clothing sets and sweat which evaporated as a percentage of the general amount of sweat secreted during studies with prototypes A, B, C and with protective clothing L2. Notes. ${ }^{*} p<.05$ among prototype $\mathrm{C}$, prototypes $\mathrm{A}$ and $\mathrm{B}$ and protective clothing $\mathrm{L} 2$. 


\subsection{Thermal Sensations}

From the 5th minute of the experiments the thermal sensations were the worst in the study with L2 clothing. The clearest differences were observed in the 20th minute of the experiments when the thermal sensations were statistically significantly $(p<.05)$ worse in L2 than in all prototypes. In the measurements with prototype A the thermal sensations deteriorated during all experiments. In measurements with prototypes B and C, however, the change was smaller (Figure 11).

\subsection{Subjective Ratings of Skin Wettedness}

From the start of the experiments the subjective ratings of skin wettedness were much worse with protective clothing L2 than with all prototypes. The differences became statistically significant in the 10th and 20th minutes of the experiments (Figure 12). Moreover, from the 20th minute until the end of the study the subjective ratings of skin wettedness were the lowest in prototype $C$ and slightly worse in prototypes A and B.

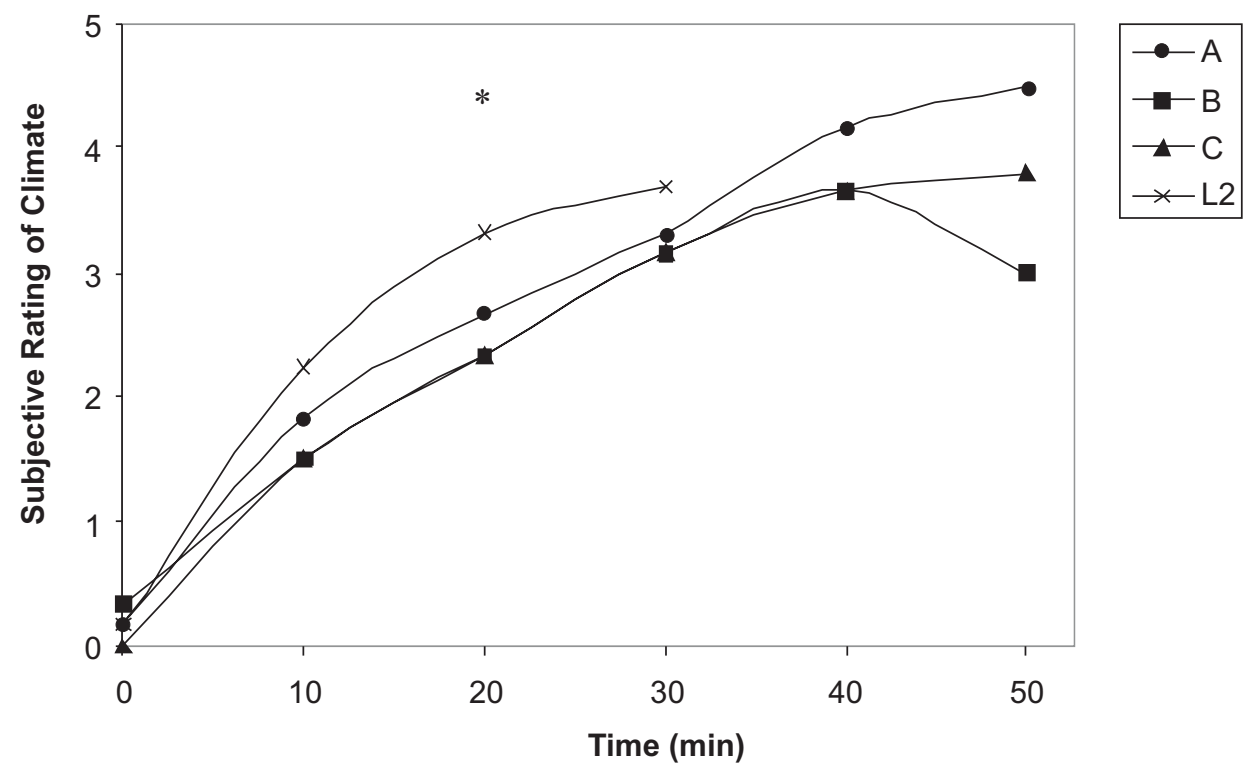

Figure 11. Time course of subjective ratings of climate during studies with prototypes A, B, C and with protective clothing L2. Notes. ${ }^{*} p<.05$ among L2 and all prototypes of protective clothing. Ratings on a 0-5 scale, where 0-neutral, 5-extremely hot.

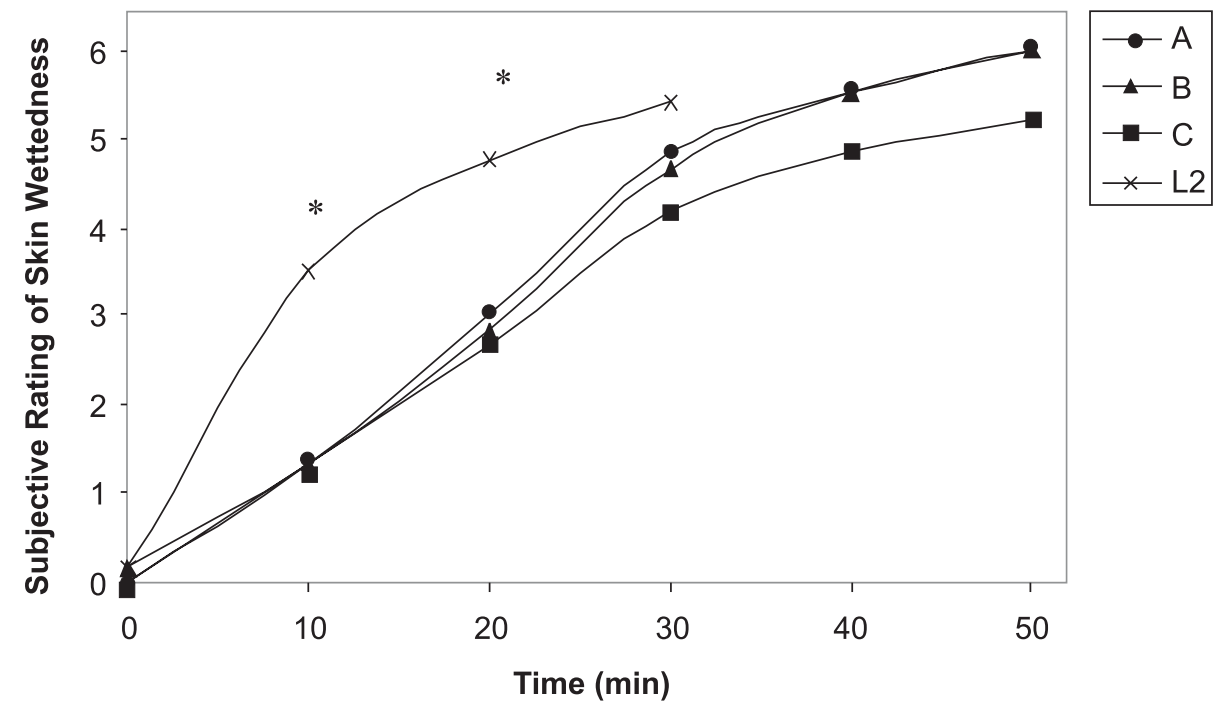

Figure 12. Time course of subjective ratings of skin wettedness during studies with prototypes $A$, B, C and with protective clothing L2. Notes. ${ }^{*} p<.05$ among L2 and all prototypes of protective clothing. Ratings on a 0-5 scale, where 0-normally dry, 6-sweat dripping in many places. 
TABLE 1. Reasons for Ending Exposure to a Hot Environment (Number of Cases).

\begin{tabular}{lccccr}
\hline & \multicolumn{5}{c}{ Protective Clothing } \\
\cline { 2 - 5 } Parameters & A & B & C & L2 & Total \\
\hline Heart rate & 1 & 1 & - & 2 & 4 \\
$t_{\text {ac }}$ & 4 & 4 & 2 & 3 & 13 \\
Relative humidity under clothing & 1 & 1 & 3 & 1 & 6 \\
Subjective signs of fatigue & - & - & 1 & - & 1 \\
\hline
\end{tabular}

Notes. $t_{\mathrm{ac}}-$ core temperature in the external auditory canal.

\subsection{Reasons for Ending an Experiment}

The most frequent reason for ending experiments was $t_{\mathrm{ac}}$, in prototypes $\mathrm{A}$ and $\mathrm{B}$ and in $\mathrm{L} 2$ clothing. In experiments with $\mathrm{L} 2$, a high level of heart rate was often a limiting factor, too. In prototypes A and $\mathrm{B}$ the reasons of ending experiments were identical. In prototype $\mathrm{C}$, most often the study ended because of high relative humidity under the clothing (Table 1); physiological parameters less frequently led to the end of the experiment.

\section{DISCUSSION}

The most interesting finding of the study was that all prototypes made work in a hot environment possible, with lower physiological strain and with better subjective ratings than in the basic model, i.e., in protective clothing $\mathrm{L} 2$, which was a basic model for modifications aimed at improving its hygienic properties. Physiological parameters, like core and skin temperatures and heart rate, had statistically significantly lower values when prototypes of protective clothing were used in experiments than L2 clothing. Moreover, humidity under the clothing confirmed that the prototypes ensured better comfort properties than protective clothing L2. The results of physiological measurements confirmed the results of the subjective ratings. Both thermal sensation and ratings of skin wettedness were statistically significantly better during exposure with all prototypes than with protective clothing L2. Better properties of the new models of protective clothing resulted in longer exposure than for L2 clothing in the same conditions of physical and thermal load.

The results of the study indicated that there were fundamental differences in sweat distribution during experiments with prototype C. During exposure in prototype $\mathrm{C}$ more sweat evaporated from the skin surface and less sweat was accumulated in all parts of the clothing compared to prototypes A and B and L2 clothing. The differences were statistically significant. Moreover, all subjects pointed to prototype $\mathrm{C}$ as the best solution for construction modification from the three proposals for lowering discomfort during work in a hot environment.

Many research studies on the effects of different technical solutions in impermeable protective clothing aimed at improving the effectiveness of thermoregulation processes in difficult ambient conditions, e.g., Turpin-Legendre and Meyer [19], who compared physiological and subjective responses during exercise in real work conditions using impermeable protective clothing. One model was made from Tyvek ${ }^{\circledR}$, the other was a ventilated Mururoa ${ }^{\circledR}$. In ventilated clothing the participants' thermal strain was lower than in clothing without ventilation. Air inflow was $700 \mathrm{~L} / \mathrm{min}$. In our study air velocity at the entrance valve was $170 \mathrm{~L} / \mathrm{min}$, so it was several times slower than in Turpin-Legendre and Meyer's study; however, the effects of improved comfort properties of protective clothing were seen and gave statistically significant differences in physiological responses compared to conditions without ventilation.

The next matter to consider was the effectiveness of improving the hygienic properties of protective clothing with refills of high sorption fabrics which have high sweat absorption [20, 21, 22]. Our study was conducted using a construction refills solution (prototype B). The results of the study indicated that refills met the requirements and absorbed sweat; however, they were not sufficiently effective. It is possible 
to improve this effectiveness by increasing the number of sorption fibres or their thickness and those possibilities could be used in the future.

Also in the solution with active ventilation (prototype C) it would be possible to apply cool air inflow to protective clothing, not hot like in our study, to improve the effectiveness of heat reception from the skin surface and then to improve the cooling of the body exposed to exo- and endogenic heat operation. Some studies indicated that cooling systems supplied with cool air or liquid were highly effective [23, 24] in reducing heat strain during exercise in a hot environment in NBC protective clothing, i.e. clothing protecting against nuclear, biological and chemical harmful agents. In our study it was also possible to apply a lighter ventilator to disturb work performance to the lowest extent.

Subjective ratings are an important factor of thermal comfort. They determine the thermal status of the body and are important for thermal regulation. Cold fabrics cause a thermal skin sensation connected with heat and moisture transfer between fabrics and the skin. This sensation is significantly influenced by the perception of comfort in different environments. Li [25] indicated that the perception of comfort was positively related to the perception of warmth and negatively to the perception of dampness. $\mathrm{Li}$ also stated that this perception of comfort was positively related to skin temperature, and nonlinearly and negatively related to relative humidity in the clothing microclimate.

Clothing layers hinder sweat evaporation from the skin surface so the permeability of fabrics to water vapour is a significant factor. The comfort of work in impermeable protective clothing is always low. Subjects acclimatized to a hot environment, e.g., fire-fighters, who were our subjects, sweat more than nonacclimatized subjects and then give back excessive heat to the environment more easily. However, during work in impermeable protective clothing this is not an advantage. Aoyagi, McLellen and Shepard [26] indicated that neither endurance training nor acclimatization to a hot environment lowered physiological strain and improved subjective ratings during work in impermeable protective clothing in a hot environment but only high physical capacity made this possible [27]. So, because impermeable protective clothing is uncomfortable, activities during accidents that involve chemical agents are considered physically and mentally extreme even for highly trained professionals who are ready to face the most difficult situations like dangerous gases, and chemical or nuclear agents.

\section{CONCLUSIONS}

New construction solutions in models of impermeable protective clothing significantly improved comfort of work because of lower thermal strain that protective clothing imposed on the user. Results indicated that all new models of protective clothing made it possible to work for 39-64\% longer than the basic model of protective clothing. The model with active ventilation was considered the best construction solution, which was supported with physiological measurements and subjective ratings.

\section{REFERENCES}

1. Holmér I. Protective clothing and heat stress. Ergonomics. 1995;38(1):166-82.

2. Bartkowiak G. Dynamics of microclimate humidity under hermetic barrier clothing. Fibres and Textiles in Eastern Europe. 2001;4:41-5.

3. Mihal JD. Effect of heat stress on physiologcal factors for industrial workers performing routine work and wearing impermeable vapor-barrier clothing. Am Ind Hyg Assoc J. 1981;42(2):97-103.

4. Ilmarinen R, Lindholm H, Koivistoinen K, Helistén P. Physiological evaluation of chemical protective suit system (CPSS) in hot conditions. International Journal of Occupational Safety and Ergonomics (JOSE). 2004;10(3):215-26.

5. Holmér I, Nilsson H, Rissanen S, Hirata K, Smolander J. Quantification of heat balance during work in three types of asbestosprotective clothing. Int Arch Environ Health. 1992; 64:243-49. 
6. Marszałek A, Smolander J, Sołtyński K. Age-related thermal strain in men while wearing radiation protective clothing during short term exercise in the heat. International Journal of Occupational Safety and Ergonomics (JOSE). 2004;10(4):361-7.

7. Marszałek A. Physiological response during exercise in a hot environment in chemical protective clothing. In: Proceedings of the 3rd European Conference on Protective Clothing and Nokobetef 8 [CD-ROM]. Gdynia, Poland: CIOP-PIB; 2006.

8. Sköldström B, Holmér I. A protective garment for hot environments with improved evaporative heat transfer. In: Proceedings of Aspects médicaux et biophysiques des vêtements de protection. Lyon, France: Centre de Recherches du Service de Santé des Armées; 1984. p. 289-94.

9. Smolander J, Louhevaara V, Tuomi O, Korhonen O, Jaakola J. Cardiorespiratory and thermal effects of wearing gas protective clothing. Int Arch Environ Health. 1984;54:261-70.

10. White MK, Hodous TK. Reduced work tolerance associated with wearing protective clothing and respirators. Am Ind Assoc J. 1987;48: 304-10.

11. Marszałek A, Sawicka A. Impermeable protective clothing-work time must be limited. In: Niesen R, Carsten Borg C, editors. Fifth Scandinavian Symposium on Protective Clothing-proceedings. Copenhagen, Denmark: NOKOBETEF. p. 100-6.

12. Council Directive 89/686/EEC of 21 December 1989 on the approximation of the laws of the Member States relating to personal protective equipment. OJ. 1989;L399:18-38. Retrieved January 5, 2009, from: http://ec.europa.eu/enterprise/ mechan_equipment/ppe/dir89-686.htm

13. European Committee for Standardization (CEN). Protective clothing against liquid chemicals-performance requirements for clothing with liquid-tight (Type 3) or spraytight (Type 4) connections, including items providing protection to parts of the body only (Types PB [3] and PB [4]) (Standard No. EN 14605:2005). Brussels, Belgium: CEN; 2005.
14. European Committee for Standardization (CEN). Protective clothing for use against liquid chemicals-test method: determination of resistance to penetration by spray (spray test) (Standard No. EN 468:1994). Brussels, Belgium: CEN; 1994.

15. European Committee for Standardization (CEN). Protective clothing for use against liquid chemicals-test method: determination of resistance to penetration by a jet of liquid (jet test) (Standard No. EN 463:1994). Brussels, Belgium: CEN; 1994.

16. European Committee for Standardization (CEN). Ergonomics - evaluation of thermal strain by physiological measurements (Standard No. EN ISO 9886:2004). Brussels, Belgium: CEN; 2004.

17. European Committee for Standardization (CEN). Ergonomics of the thermal environment-assessment of the influence of the thermal environment using subjective judgement scales (Standard No. EN ISO 10551:2001). Brussels, Belgium: CEN; 2004.

18. Nielsen R, Endrusick TL. Sensations of temperature and humidity during alternative work/rest and influence of underwear knit structure. Ergonomics. 1990;33(2):221-34.

19. Turpin-Legendre E, Meyer JP. Comparison of physiological and subjective strain in workers wearing two different protective coveralls for asbestos abatement tasks. Appl Ergon. 2003;34:551-6.

20. Bartkowiak G. Właściwości biofizyczne materiałów na odzież ochronną [Biophysical properties of fabrics for protecting clothing]. Bezpieczeństwo Pracy. 1998;7-8: 17-20.

21. Bartkowiak G. Badania konstrukcji materiałowych z udziałem superabsorbentów pod szczelnymi ubiorami ochronnymi dla poprawy komfortu ich użytkowania [Study of fabric construction with a participation of high sorption fabrics under tight protective clothing for improving users comfort] [unpublished report]. Warszawa, Poland: Central Institute for Labour Protection - National Research Institute; 2004.

22. Bartkowiak G, Marszałek A. Dwustopniowy model badania właściwości biofizycznych odzieży ochronnej [Two-level 
model of studying biophysical properties of protective clothing]. Przegląd Włókienniczy + Technik Włókienniczy. 1999;3:9-14.

23. McLellan TM, Frim MA, Bell DG. Efficacy of air and liquid cooling light and heavy exercise while wearing NBC clothing. Aviat Space Environ Med. 1999;70(8):802-11.

24. Cadarette BS, Cheuvront SN, Kolka MA, Stephenson LA, Montain SJ, Sawka MN. Intermittent microclimate cooling during exercise-heat stress in US army chemical protective clothing. Ergonomics. 2006; 49(2):209-29.
25. Li Y. Perceptions of temperature, moisture and comfort in clothing during environmental transients. Ergonomics. 2005;48(3):234-48.

26. Aoyagi Y, McLellen TM, Shepard R. Effects of endurance training and heat acclimation on psychological strain in exercise men wearing protective clothing. Ergonomics. 1998;41(3):328-57.

27. Louhevara V, Ilmarinen R, Griefahn B, Künemund C, Mäkinen H. Maximal physical work performance with European standard based fire-protective clothing system and eqiupment in relation to individual characteristic. Eur J Appl Physiol. 1995;71:223-9. 